\title{
Tri-modal Microstructure in Different Loading Zones Under TA15 Ti-alloy Isothermal Local Conventional Forging and Given Subsequent Heat Treatment
}

\author{
Zhichao Sun ${ }^{a, b *}{ }^{(0)}$, Long Huang ${ }^{a, b}$, Jing Cao ${ }^{a}$, Zhikun Yin ${ }^{a}$ \\ ${ }^{a}$ Research \& Development Institute of Northwestern Polytechnical University in Shenzhen, Shenzhen, \\ Guangdong, 518057, China \\ ${ }^{b}$ State Key Lab of Solidification Processing, Department of Materials Science and Engineering, \\ Northwestern Polytechnical University, P. O. Box 542, Xi'an, Shaanxi, 710072, China
}

Received: November 27, 2018; Revised: March 27, 2019; Accepted: April 29, 2019

For TA15 Ti-alloy large-scale component, isothermal local conventional forging (ILCF) combined with subsequent heat treatment provides a feasible approach to obtain a tri-modal microstructure with attractive comprehensive performance. However the tri-modal microstructure characteristics and evolution laws in the first and second loading zones are lack of understanding. In this paper, the effects of ILCF conditions on the tri-modal microstructure in the first and second loading zones were investigated under given subsequent heat treatment and the reasonable ILCF conditions were proposed. As forging temperature increases, in both loading zones the content and aspect of equiaxed $\alpha_{\mathrm{p}}$ decrease obviously while the content and thickness of lamellar $\alpha_{\mathrm{s}}$ increase. The content and thickness of lamellar $\alpha_{\mathrm{s}}$ in the second loading zone are higher. Forged at a moderate strain rate of $0.1 \mathrm{~s}^{-1}$, the content of lamellar $\alpha_{\mathrm{s}}$ is higher, and the differences in the content and morphology of constituent phases in both loading zones are relatively small. Compared with air cooling after forging, water quenching result in more and disordered lamellar $\alpha$, and less differences in obtained tri-modal microstructure in the first and second loading zones. Under three loading passes, the uniformity of tri-modal microstructure in the first and second loading zones is better.

Keywords: TA15 Ti-alloy, Isothermal local conventional forging, Tri-modal microstructure, Processing parameters.

\section{Introduction}

TA15 Ti-alloy is extensively used to manufacture largescale complex components as long-duration and load-bearing structures in aviation and aerospace fields ${ }^{1,2}$. Due to the high deformation resistance of material, complex shape and large projection area of these components, isothermal local loading (ILL) forming technology ${ }^{3}$ (Fig. 1), in which load is applied to part of the billet and the component is formed by changing the loading zones, provides a possible way to form them. The ILL combines the advantages of isothermal forming and local loading forging, improving the plasticity and formability of material, controlling material flow and reducing forming load ${ }^{4}$. However, in the ILL process of large-scale integral component there exist the first and second loading zones experiencing different hot working processes. This will cause differences in morphology and content of constituent phases, stored distortion energy and crystal defects in forged microstructure of the first and second loading zones, which would have a great impact on the microstructure evolution behavior during subsequent heat treatment due to the microstructure heredity, as a consequence differences in the final microstructure may occur in different loading zones ${ }^{5}$.
Due to the extreme service conditions for these largescale complex components of TA15 Ti-alloy, the excellent comprehensive mechanical performance is required ${ }^{6}$. For Ti-alloys a tri-modal microstructure, consisting of equiaxed $\alpha_{\mathrm{p}}$, lamellar $\alpha_{\mathrm{s}}$, and transformed $\beta$ matrix, exhibits a good combination of strength, ductility, fracture toughness and fatigue life. There are some methods to obtain tri-modal microstructure. Zhou et al. ${ }^{6}$ proposed a near- $\beta$ forging technique and obtained a tri-modal microstructure with good mechanical properties. Zhu et al. ${ }^{7}$ proposed a two-step heat treatments method to obtain a tri-modal microstructure. However, the near- $\beta$ forging temperature is high and may lead to grains coarsening, and two-step heat treatments method required an original microstructure of bimodal structure. Sun et al. ${ }^{8}$ obtained a tri-modal microstructure for TA15

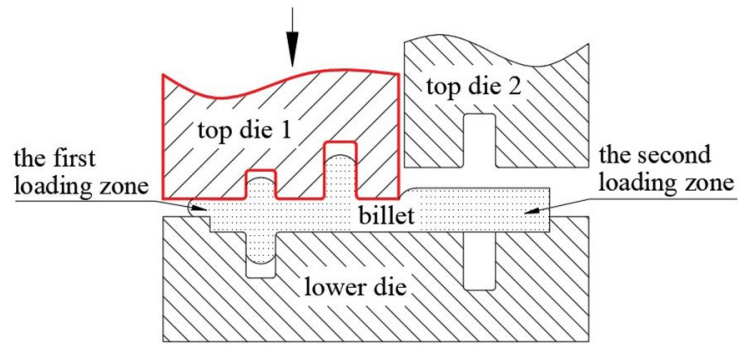

Figure 1. Schematic diagram of local loading forming. 
Ti-alloy though isothermal conventional forging technique, and it can solve the problems mentioned above. Therefore, isothermal local conventional forging (ILCF) technology can be used to form large-scale component with tri-modal microstructure. However, the tri-modal microstructure, strictly with the phase constituent, morphology, size and distribution, is largely determined by processing parameters in hot working process ${ }^{9}$. Furthermore, the ILCF of large-scale component is a multi-step process with complex thermal cycling routes, which greatly influences the development of tri-modal microstructure ${ }^{10}$. Consequently, in order to obtain uniform tri-modal microstructure in different loading zones with excellent comprehensive properties required by harsh working conditions, it is necessary to study the influence of the ILCF parameters on tri-modal microstructure evolution laws in TA15 Ti-alloy forming.

Some studies on the effect of processing parameters conducted in the ILCF on the tri-modal microstructure characteristics and evolution laws were investigated. Sun et al. ${ }^{11}$ quantitatively studied the evolution laws of volume fraction, average grain size and aspect ratio of equiaxed $\alpha_{p}$ under different deformation temperatures, degrees and strain rates in forging process and given subsequent heat treatment. Fan et al. ${ }^{12}$ pointed out that tri-modal structure could be achieved by near- $\beta$ forging followed by conventional forging and the volume fraction of each constituent phase in tri-modal structure was determined by the heating temperature of the last two loading steps. Sun et al. ${ }^{9}$ revealed the dependence of forming conditions on the obtained tri-modal microstructure and quantitatively investigated the evolution laws of equiaxed $\alpha_{p}$ and lamellar $\alpha_{s}$ in different forging conditions (forging temperature, deformation degree, strain rate, cooling mode). Those results above show that forming conditions have a great impact on tri-modal microstructure, but they mainly focus on integral forming process. Gao et al. ${ }^{13}$ studied the effect of different loading routes on microstructure evolution under multi-step local loading forming, and mainly revealed the importance of forging temperature for obtaining trimodal microstructure. Gao et al. ${ }^{10}$ investigated the effect of processing parameters on the development of tri-modal microstructure during the isothermal local loading of TA15 Ti-alloy. However, there are still lack of quantitative analysis for the effect of the ILCF parameters on the tri-modal microstructure of different loading zones.

In this paper, the effects of ILCF parameters on tri-modal microstructure in the first and second loading zones during TA15 Ti-alloy ILCF and given subsequent heat treatment were quantitatively investigated by different process schemes. The results will provide guidance for selecting reasonable ILCF conditions to obtain a tri-modal microstructure with excellent properties.

\section{Material and Experimental Procedures}

\subsection{Material}

The TA15 Ti-alloy with an $\alpha \rightarrow \beta$ transition temperature of about $990{ }^{\circ} \mathrm{C}$ was from Western Superconduction Technologies Inc, and its chemical composition was listed in Table 1. The microstructure of as-received material is equiaxed microstructure and consists of about $60 \%$ equiaxed $\alpha_{\mathrm{p}}$ (with a standard deviation of 3.0\%) and transformed $\beta$ matrix, as shown in Fig. 2. The average grain size of the equiaxed $\alpha_{\mathrm{p}}$ is about $11.0 \mu \mathrm{m}$.

\subsection{Experimental procedures}

The cylindrical specimens with a diameter of $10.0 \mathrm{~mm}$ and a height of $15.0 \mathrm{~mm}$ were machined from the as-received blank, $2 \mathrm{~mm}$ shallow grooves were processed on the upper and lower ends so as to store high temperature lubricant (glass lubricant). The conventional forging was simulated on the SANS universal testing machine. Specifically, the TA15 specimens were heated to the conventional forging temperature at a rate of $15^{\circ} \mathrm{C} \mathrm{m^{-1 }}$ and held for $10 \mathrm{~min}$ to achieve thermal equilibrium and then compressed.

In order to investigate the effects of ILCF parameters on tri-modal microstructure in the first and second loading zones, conventional forging parameters are set as follows: deformation temperatures of $930^{\circ} \mathrm{C}, 940^{\circ} \mathrm{C}, 950^{\circ} \mathrm{C}, 960^{\circ} \mathrm{C}$; strain rates of $0.1 \mathrm{~s}^{-1}$ and $0.01 \mathrm{~s}^{-1}$; loading pass of one, two and three (total deformation degree of $60 \%$ ) and cooling modes of air cooling (AC) and water quenching (WQ). Table 2 shows experimental schemes used in the ILCF, the effect of deformation temperature corresponding to tests 7 , 5,8 and 9 , the effect of strain rate corresponding to tests 5 and 13, the effect of cooling mode corresponding to tests 5 and 12 , and the effect of loading pass corresponding to tests 2,5 , and 6 .

Two samples were used in each loading step to simulate the first and second loading zones during ILCF. For example, test 5 in Table 2 is the two loading passes forging $\left(940^{\circ} \mathrm{C} / 0.1 \mathrm{~s}^{-1} /\right.$ $\mathrm{WQ} / 2$ ) and consists of four loading steps in each loading zone. The detailed scheme of test 5 is shown in Table 3 , and the thermal processing route displayed in Fig. 3 for the first 
Table 1. Chemical constitution of TA15 Ti-alloy.

\begin{tabular}{|c|c|c|c|c|c|c|c|c|c|c|c|}
\hline Element & Al & $\mathbf{Z r}$ & Мо & $\mathbf{V}$ & Si & $\mathbf{C}$ & $\mathbf{F e}$ & $\mathbf{O}$ & $\mathbf{N}$ & $\mathbf{H}$ & $\mathbf{T i}$ \\
\hline $\begin{array}{l}\text { Nominal } \\
\text { composition/\% }\end{array}$ & $\begin{array}{l}6.63- \\
6.75\end{array}$ & $\begin{array}{l}2.23- \\
2.27\end{array}$ & $\begin{array}{l}1.73- \\
1.80\end{array}$ & $\begin{array}{l}2.24- \\
2.27\end{array}$ & $<0.04$ & $<0.006$ & 0.14 & 0.12 & $<0.002$ & 0.002 & Balance \\
\hline
\end{tabular}

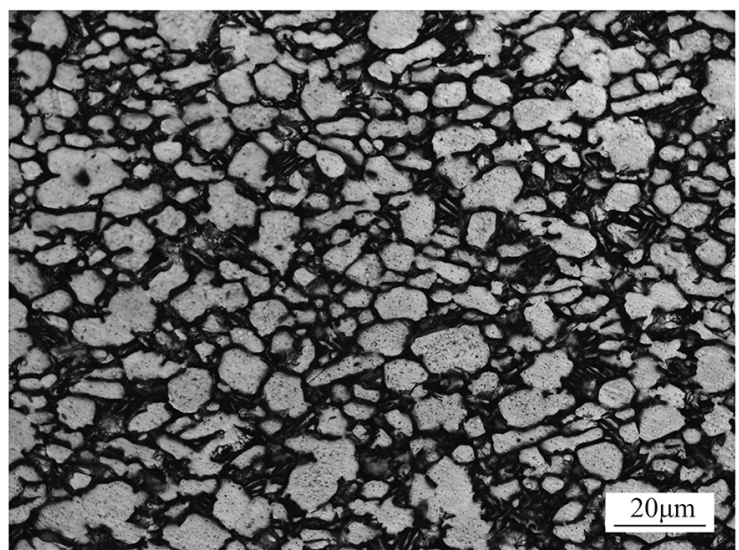

Figure 2. Original microstructure of TA15 Ti-alloy.

loading zone was as follows, (1) $940^{\circ} \mathrm{C} / 8 \mathrm{~min}, 30 \%$ reduction, WQ; (2) $940^{\circ} \mathrm{C} / 10 \mathrm{~min}$, WQ; (3) $940^{\circ} \mathrm{C} / 8 \mathrm{~min}, 30 \%$ reduction, WQ; (4) $940^{\circ} \mathrm{C} / 10 \mathrm{~min}$, WQ. The heat treatment route used for the samples after forging was near- $\beta+$ two-phase field heat treatments $\left(\mathrm{NTH}, 975 / 30 \mathrm{~min} / \mathrm{WQ}+930^{\circ} \mathrm{C} / 1.5 \mathrm{~h} / \mathrm{AC}\right)$.

After experiments, the specimens were sectioned axially for micrographic observation in the central portion of each specimen. The specimens were mechanically polished and etched with a solution consisting of $13 \% \mathrm{HF}, 7 \% \mathrm{HNO} 3$, and $80 \% \mathrm{H}_{2} \mathrm{O}$ (volume fraction). The micrograph observation was implemented by the OLYMPUS PMG3 metallographic microscope and quantitative analysis was carried out by using Image-Pro Plus 5.0 image analysis software. For each sample, various magnifications $(200,500,1000)$ were taken

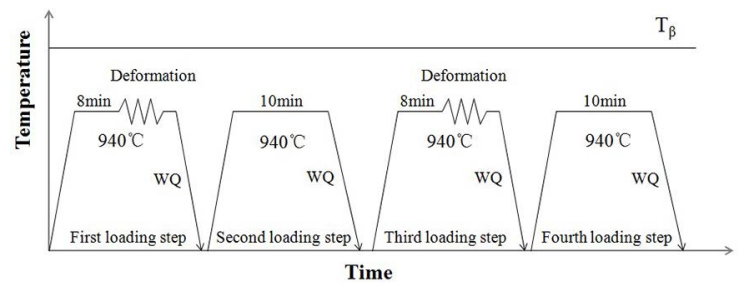

Figure 3. Schematic of local conventional forging route in the first loading zone (two passes).

to observe the microstructures at different locations (at least five locations).

\section{Influence of ILCF Parameters on tri- modal Microstructure in the First and Second Loading Zones}

\subsection{Influence of deformation temperature}

Fig. 4 shows the obtained micrographs of different loading zones after ILCF $\left(0.1 \mathrm{~s}^{-1} / \mathrm{WQ} / 60 \% / 2\right)$ under different temperatures of $930-960^{\circ} \mathrm{C}$ combined with given NTH $\left(975^{\circ} \mathrm{C} / 0.5 \mathrm{~h} / \mathrm{WQ}\right.$ $\left.+930^{\circ} \mathrm{C} / 1.5 \mathrm{~h} / \mathrm{AC}\right)$. Fig. 5 presents the measured results of microstructure parameters. As shown in Figs. 4 and 5, the microstructure constituents in the first and second loading zones are similar, both of them are composed of equiaxed $\alpha_{p}$, lamellar $\alpha_{s}$ and transformed $\beta$ matrix. As the deformation temperature increases from $930^{\circ} \mathrm{C}$ to $960^{\circ} \mathrm{C}$, the volume fraction of equiaxed $\alpha_{\mathrm{p}}$ decreases from $13.8 \%$ to $9.1 \%$ in first loading zone and from $13.4 \%$ to $8.9 \%$ in second loading

Table 2. Experimental schemes of local conventional forging.

\begin{tabular}{|c|c|c|c|c|c|}
\hline No & $\begin{array}{c}\text { Deformation } \\
\text { temperature }\left({ }^{\circ} \mathrm{C}\right)\end{array}$ & $\begin{array}{l}\text { Deformation } \\
\text { amount (\%) }\end{array}$ & Strain rate $\left(\mathrm{s}^{-1}\right)$ & Loading pass & Cooling mode \\
\hline 1 & 930 & 60 & 0.1 & 1 & WQ \\
\hline 2 & 940 & 60 & 0.1 & 1 & WQ \\
\hline 3 & 950 & 60 & 0.1 & 1 & WQ \\
\hline 4 & 960 & 60 & 0.1 & 1 & WQ \\
\hline 5 & 940 & 60 & 0.1 & 2 & WQ \\
\hline 6 & 940 & 60 & 0.1 & 3 & WQ \\
\hline 7 & 930 & 60 & 0.1 & 2 & WQ \\
\hline 8 & 950 & 60 & 0.1 & 2 & WQ \\
\hline 9 & 960 & 60 & 0.1 & 2 & WQ \\
\hline 10 & 940 & 60 & 0.1 & 1 & $\mathrm{AC}$ \\
\hline 11 & 940 & 60 & 0.01 & 1 & WQ \\
\hline 12 & 940 & 60 & 0.1 & 2 & $\mathrm{AC}$ \\
\hline 13 & 940 & 60 & 0.01 & 2 & WQ \\
\hline
\end{tabular}


Table 3. The detailed scheme of test 5.

\begin{tabular}{|c|c|c|c|c|}
\hline Test No & $\begin{array}{c}\text { Temperature of the first } \\
\text { loading step }\end{array}$ & $\begin{array}{l}\text { Deformation amount of } \\
\text { the first loading step }\end{array}$ & $\begin{array}{c}\text { Temperature of the second } \\
\text { loading step }\end{array}$ & $\begin{array}{l}\text { Deformation amount of } \\
\text { the second loading step }\end{array}$ \\
\hline $5-\mathrm{a}$ & \multirow{2}{*}{$940^{\circ} \mathrm{C}$} & $30 \%$ & \multirow{2}{*}{$940^{\circ} \mathrm{C}$} & $0 \%$ \\
\hline $5-b$ & & $0 \%$ & & $30 \%$ \\
\hline Test No & $\begin{array}{c}\text { Temperature of the third } \\
\text { loading step }\end{array}$ & $\begin{array}{l}\text { Deformation amount of } \\
\text { the third loading step }\end{array}$ & $\begin{array}{l}\text { Temperature of the fourth } \\
\text { loading step }\end{array}$ & $\begin{array}{l}\text { Deformation amount of } \\
\text { the fourth loading step }\end{array}$ \\
\hline $5-\mathrm{a}$ & \multirow{2}{*}{$940^{\circ} \mathrm{C}$} & $30 \%$ & \multirow{2}{*}{$940^{\circ} \mathrm{C}$} & $0 \%$ \\
\hline $5-b$ & & $0 \%$ & & $30 \%$ \\
\hline
\end{tabular}

Notes: the strain rate of each loading step is $0.1 \mathrm{~s}^{-1}$, and the cooling mode after forging is WQ.
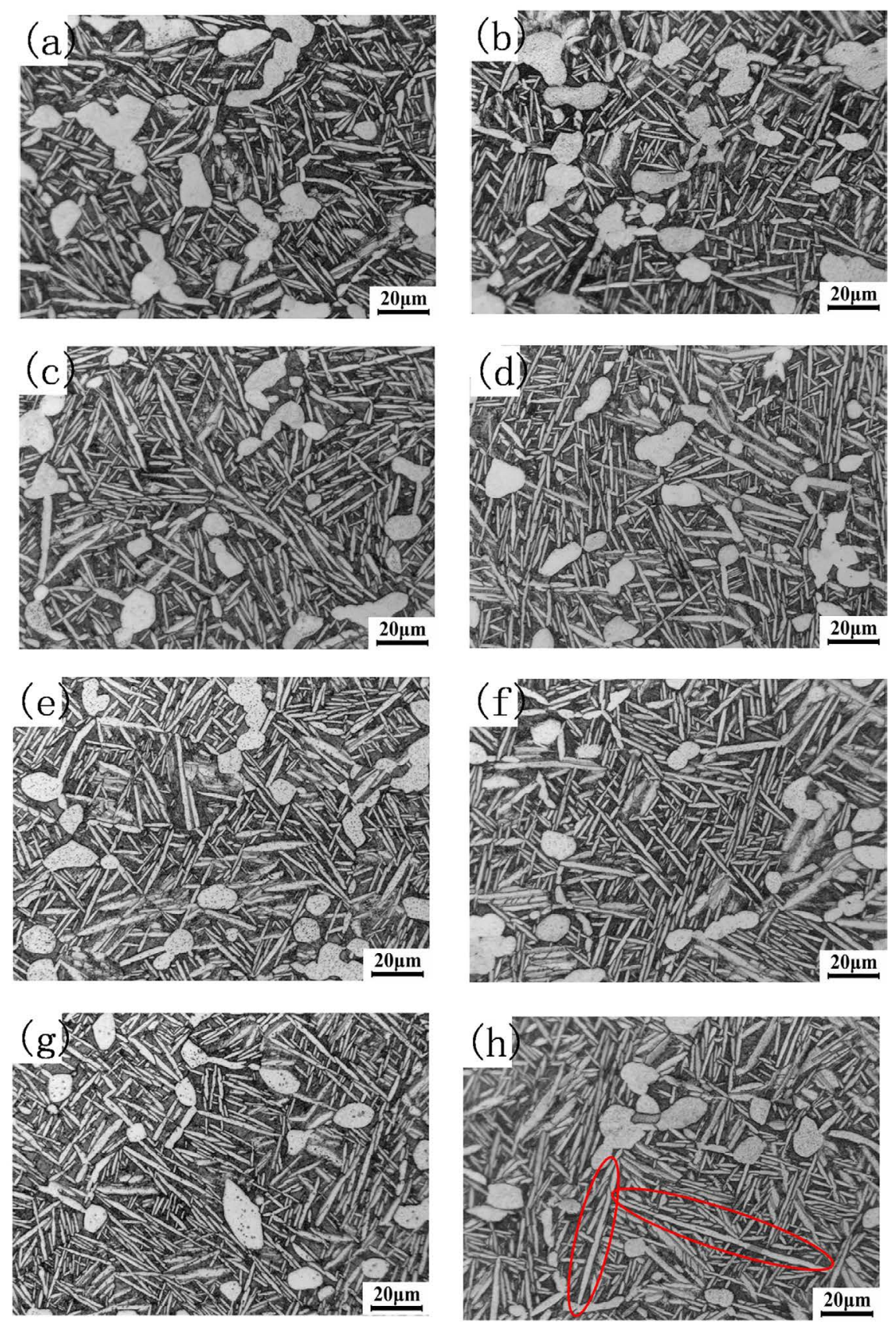

Figure 4. Micrographs of different loading zones after ILCF $\left(0.1 \mathrm{~s}^{-1} / \mathrm{WQ} / 60 \% / 2\right)$ at different temperatures combined with NTH $\left(975^{\circ} \mathrm{C} / 0.5 \mathrm{~h} / \mathrm{WQ}+930^{\circ} \mathrm{C} / 1.5 \mathrm{~h} / \mathrm{AC}\right.$ ): (a), (b) $930^{\circ} \mathrm{C}$; (c), (d) $940^{\circ} \mathrm{C}$; (e), (f) $950^{\circ} \mathrm{C}$; (g), (h) $960^{\circ} \mathrm{C}((\mathrm{a}),(\mathrm{c}),(\mathrm{e}),(\mathrm{g})$ the first loading zone; (b), (d), (f), (h) the second loading zone). 


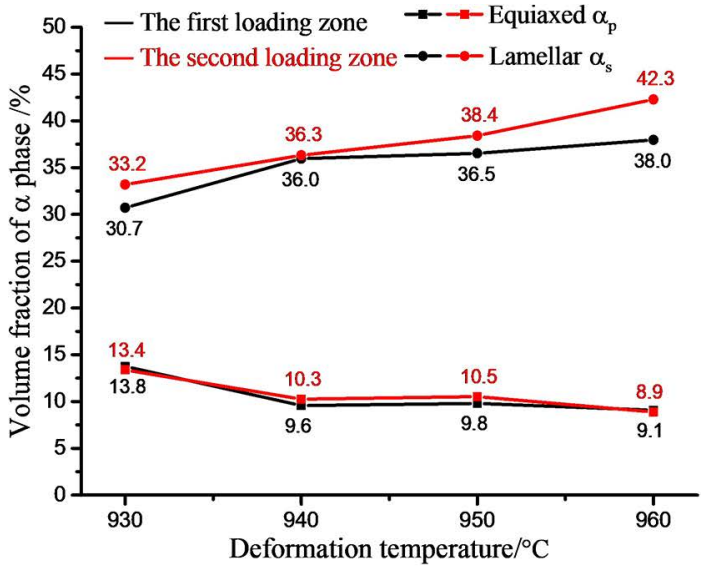

(a)

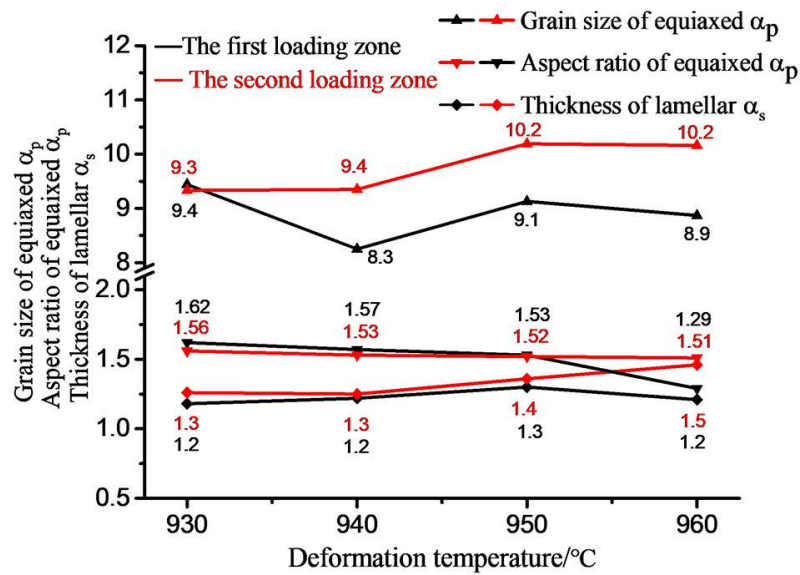

(b)

Figure 5. Microstructure parameters of different loading zones after ILCF $\left(60 \% / 0.1 \mathrm{~s}^{-1} / 2 / \mathrm{WQ}\right)$ at different temperatures combined with given $\mathrm{NTH}\left(975^{\circ} \mathrm{C} / 0.5 \mathrm{~h} / \mathrm{WQ}+930^{\circ} \mathrm{C} / 1.5 \mathrm{~h} / \mathrm{AC}\right)$ : (a) volume fraction of $\alpha$ phase; (b) average grain size and aspect of equiaxed $\alpha_{\mathrm{p}}$, thickness of lamellar $\alpha_{\mathrm{s}}$.

zone due to the fierce $\alpha \rightarrow \beta$ phase transformation during ILCF process. In addition, the higher temperature promotes the dislocations climbing and cross slip process, resulting in a reduction in dislocation density. Consequently, the crystal defects and distortion energy per unit volume are released and the lattice distortion partially disappear ${ }^{14}$. As a result, the growth of equiaxed $\alpha_{p}$ is not sufficient in subsequent heat treatment. While the volume fraction of lamellar $\alpha_{\mathrm{s}}$ increases gradually from $30.7 \%$ to $38 \%$ in first loading zone and from $33.2 \%$ to $42.3 \%$ in second loading zone. Since the content of the $\alpha$-stable element in microstructure is determined, the reduction of the equiaxed $\alpha_{\mathrm{p}}$ increases the supersaturation of the $\alpha$-stable element in the $\beta$ matrix, thereby promoting the precipitation of lamellar $\alpha_{s}^{15}$. However, the content of lamellar $\alpha_{\mathrm{s}}$ in the second loading zone is higher than that of in the first loading zone under different deformation temperatures. This is because in the second loading zone the last loading step undergoing deformation process, lots of crystal defects and distortion energy accumulate, which provides the driving force for the nucleation and growth of lamellar $\alpha_{s}$ in the subsequent heat treatment, then increasing the content of lamellar $\alpha_{s}$.

As shown in Figs. 4 and 5, the aspect of equiaxed $\alpha_{p}$ shows a decreasing trend with the increase of deformation temperature, and the aspect of equiaxed $\alpha_{p}$ in the second loading zone is smaller. This is because the $\alpha$ phase is much harder than the $\beta$ phase and then it acts as a dispersion of hard particles in a soft matrix during deformation. The content of the $\beta$ phase increases with the increase of deformation temperature, which makes the equiaxed $\alpha_{\mathrm{p}}$ experiences smaller deformation, then leading to a decrease in the aspect of equiaxed $\alpha_{\mathrm{p}}$. And in the second loading zone more accumulated distortion energy promote the spheroidization and growth of the equiaxed $\alpha_{\mathrm{p}}$ during the subsequent heat treatment. This also explains why the grain size of equiaxed $\alpha_{p}$ in the second loading zone is larger than that of in the first loading zone. The thickness of lamellar $\alpha_{\mathrm{s}}$ show an increasing trend since more crystal defects and distortion energy accumulate at lower deformation temperature, which is favorable to the nucleation and growth of lamellar $\alpha_{\mathrm{s}}$ during subsequent heat treatment. While the dynamic recovery and recrystallization strengthen when deformed at higher temperature, resulting in the decrease of crystal defects and distortion energy, which further makes the nucleation rate of lamellar $\alpha_{s}$ reduce in subsequent heat treatment. Sun et al. ${ }^{8}$ found that the nucleation rate was inversely proportional to the thickness of lamellar $\alpha_{\mathrm{s}}$, the larger nucleation rate implied smaller thickness. Meanwhile, it is found in Fig. 4 (h) that the length of individual lamellar $\alpha_{\mathrm{s}}$ is very long. This is because the $\beta$ grain coarsens obviously at higher temperature $\left(960^{\circ} \mathrm{C}\right)$, in subsequent heat treatment the individual lamellar $\alpha_{\mathrm{s}}$ preferentially grows up at high energy crystal defect in the second loading zone, which will be detrimental to crack propagation resistance.

\subsection{Influence of strain rate}

Fig. 6 shows the obtained micrographs of different loading zones after ILCF $\left(940^{\circ} \mathrm{C} / \mathrm{WQ} / 60 \% / 2\right)$ under different strain rates of $0.01 \mathrm{~s}^{-1}$ and $0.1 \mathrm{~s}^{-1}$ combined with given NTH $\left(975^{\circ} \mathrm{C} / 0.5 \mathrm{~h} / \mathrm{WQ}+930^{\circ} \mathrm{C} / 1.5 \mathrm{~h} / \mathrm{AC}\right)$. Fig. 7 presents the measured results of microstructure parameters. As shown in Figs. 6 and 7(a), as strain rate increases from $0.01 \mathrm{~s}^{-1}$ to $0.1 \mathrm{~s}^{-1}$, the content of equiaxed $\alpha_{\mathrm{p}}$ shows a decreasing trend, reducing from $16.8 \%$ to $9.6 \%$ in the first loading zone and from $11.9 \%$ to $10.3 \%$ in the second loading zone. Due to the poor thermal conductivity of Ti-alloy, the heat production is difficult to conduct at a higher strain rate $\left(0.1 \mathrm{~s}^{-1}\right)$, which results in an increase in temperature and further promotes $\alpha \rightarrow \beta$ phase transformation during ILCF. While the content of lamellar $\alpha_{\mathrm{s}}$ shows an upward trend, increasing from 

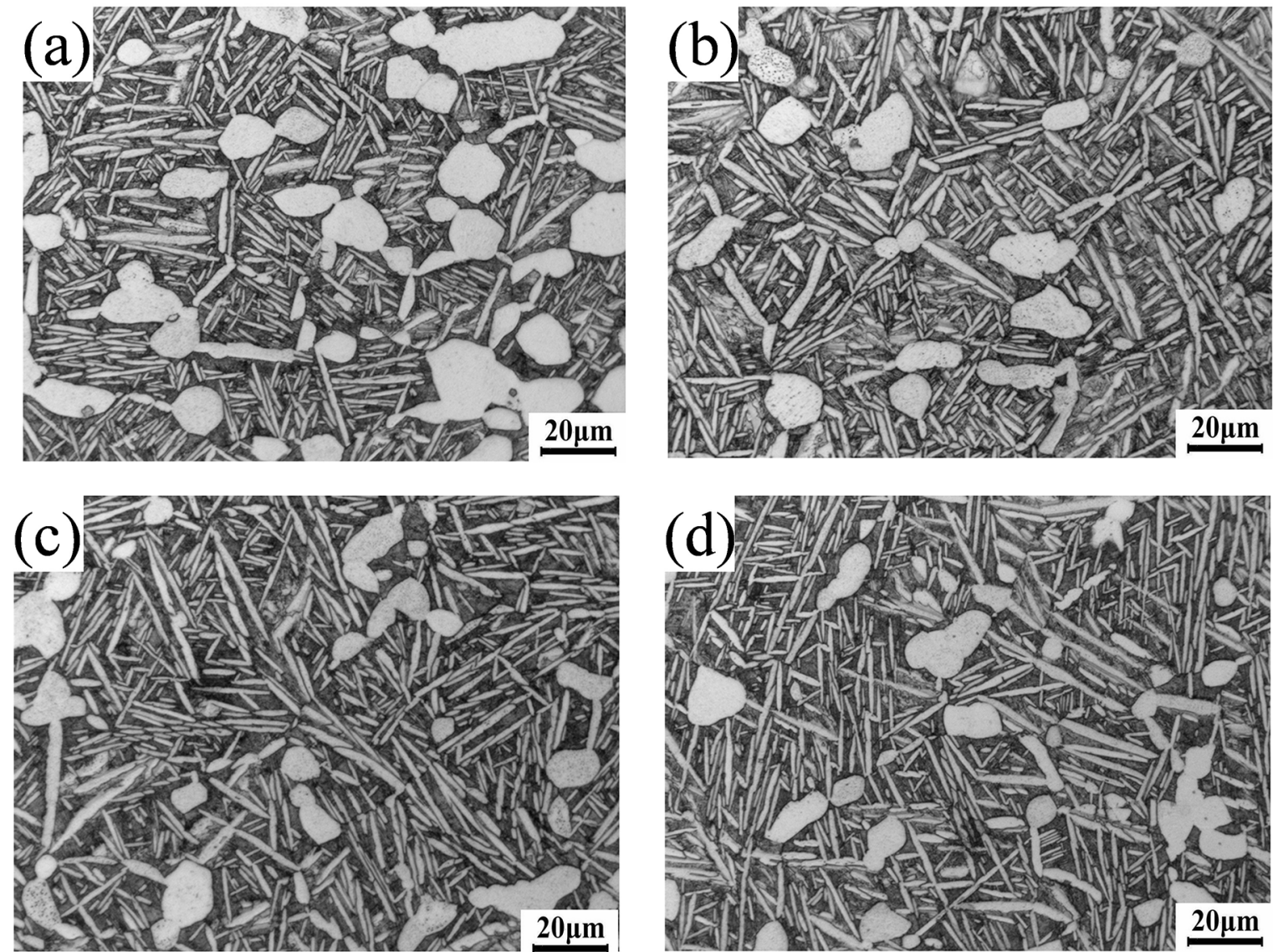

Figure 6. Micrographs of different loading zones after ILCF $\left(940^{\circ} \mathrm{C} / \mathrm{WQ} / 60 \% / 2\right)$ at different strain rates combined with given NTH $\left(975^{\circ} \mathrm{C} / 0.5 \mathrm{~h} / \mathrm{WQ}+930^{\circ} \mathrm{C} / 1.5 \mathrm{~h} / \mathrm{AC}\right)$ : (a), (b) $0.01 \mathrm{~s}^{-1}$; (c), (d) $0.1 \mathrm{~s}^{-1}$ ( (a), (c) the first loading zone; (b), (d) the second loading zone).

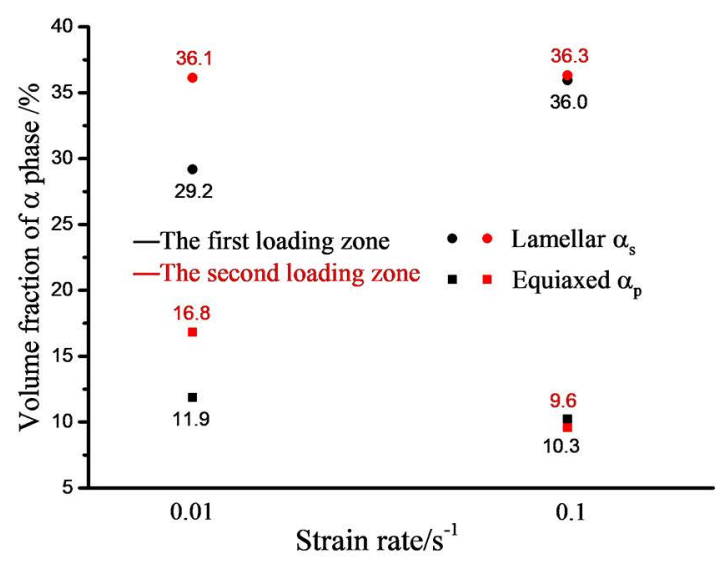

(a)

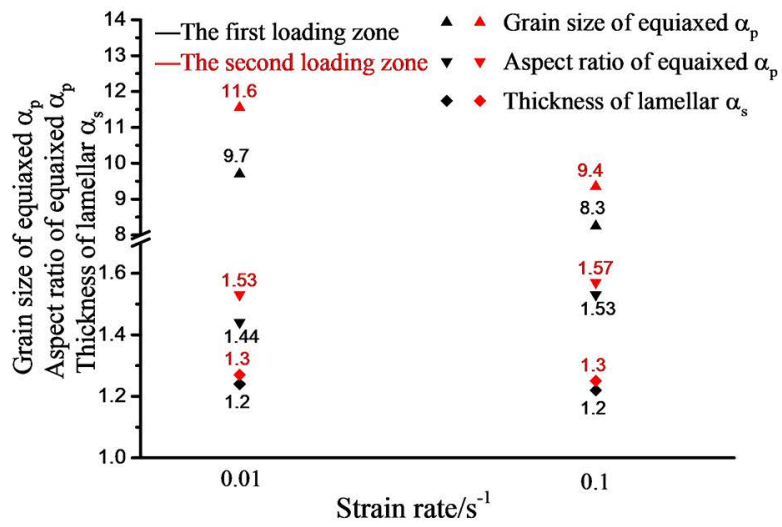

(b)

Figure 7. Microstructure parameters of different loading zones after ILCF $\left(940^{\circ} \mathrm{C} / \mathrm{WQ} / 60 \% / 2\right)$ under different strain rates combined with given NTH $\left(975^{\circ} \mathrm{C} / 0.5 \mathrm{~h} / \mathrm{WQ}+930^{\circ} \mathrm{C} / 1.5 \mathrm{~h} / \mathrm{AC}\right)$ : (a) volume fraction of $\alpha$ phase; (b) average grain size and aspect of equiaxed $\alpha_{\mathrm{p}}$, thickness of lamellar $\alpha_{\mathrm{s}}$.

$29.2 \%$ to $36.0 \%$ in the first loading zone and from $36.1 \%$ to $36.3 \%$ in the second loading zone. Forged at a higher strain rate $\left(0.1 \mathrm{~s}^{-1}\right)$, the crystal defects and distortion energy accumulate quickly without sufficient time to dissipate, and reserve largely after forging and WQ, which provides driving force to nucleation and growth of lamellar $\alpha_{\mathrm{s}}$ during subsequent heat treatment.

As shown in Figs. 6 and 7(b), as strain rate increases from $0.01 \mathrm{~s}^{-1}$ to $0.1 \mathrm{~s}^{-1}$, the grain size of equiaxed $\alpha_{\mathrm{p}}$ decreases from 9.7 to 8.3 in first loading zone and from 11.6 to 9.4 
in second loading zone. The aspect of equiaxed $\alpha_{\mathrm{p}}$ shows a small upward trend. On one hand, when forging at a higher strain rate $\left(0.1 \mathrm{~s}^{-1}\right)$, there is not enough time for equiaxed $\alpha_{\mathrm{p}}$ to grow up and spheroidize during ILCF. On the other hand, the more accumulated dislocation refines equiaxed $\alpha_{\mathrm{p}}$ by continuous recrystallization during subsequence heat treatment ${ }^{16}$. By comparing the tri-modal microstructure obtained by different strain rates, deformed at a higher strain rate of $0.1 \mathrm{~s}^{-1}$, not only the content of lamellar $\alpha_{\mathrm{s}}$ is higher, but also the differences in the content and morphology of constituent phases are smaller in both loading zones.

\subsection{Influence of cooling mode}

Fig. 8 shows the obtained micrographs of different loading zones after ILCF $\left(940^{\circ} \mathrm{C} / 60 \% / 0.1 \mathrm{~s}^{-1} / 2\right)$ under different cooling modes of WQ and AC combined with given NTH $\left(975^{\circ} \mathrm{C} / 0.5 \mathrm{~h} / \mathrm{WQ}+930^{\circ} \mathrm{C} / 1.5 \mathrm{~h} / \mathrm{AC}\right)$. Fig. 9 presents the measured results of microstructure parameters. As shown in Figs. 8 and 9, quenched by water after forging, there are relatively less content and smaller grain size of equiaxed $\alpha_{p}$ in the final microstructure. This is because the growth of equiaxed $\alpha_{\mathrm{p}}$ is inhibited during WQ, while there is more time for equiaxed $\alpha_{\mathrm{p}}$ to grow up and aggregate during $\mathrm{AC}{ }^{17}$.
When cooled by WQ after forging, the content of lamellar $\alpha_{s}$ is larger while the thickness of it is thinner. Meanwhile, the distribution of lamellar $\alpha_{\mathrm{s}}$ is relatively interlaced and disordered. This is because crystal defects caused by forging could be largely kept to room temperature by WQ, which provides the preferred nucleation site of lamellar $\alpha_{\mathrm{s}}$ and promotes the growth during subsequent heat treatment. It is also found that cooled by WQ after forging, the differences in size, content and morphology of $\alpha$ phase of final tri-modal microstructure are smaller in both loading zones.

\subsection{Influence of loading pass}

Fig. 10 shows the obtained micrographs of different loading zones after ILCF $\left(940^{\circ} \mathrm{C} / 60 \% / 0.1 \mathrm{~s}^{-1} / \mathrm{WQ}\right)$ under different loading passes of one, two and three combined with given $\mathrm{NTH}\left(975^{\circ} \mathrm{C} / 0.5 \mathrm{~h} / \mathrm{WQ}+930^{\circ} \mathrm{C} / 1.5 \mathrm{~h} / \mathrm{AC}\right)$. Fig. 11 presents the measured results of microstructure parameters. As shown in Figs. 10 and 11, as loading pass increases, the volume fraction of equiaxed $\alpha_{\mathrm{p}}$ in both loading zones decreases first and then increases, from $11.1 \%$ to $9.6 \%$ first and then decreases to $10.4 \%$ in the first loading zone, from $12.1 \%$ to $10.3 \%$ first and then decreases to $10.7 \%$ in the second loading zone. On one hand, in one loading pass forging the
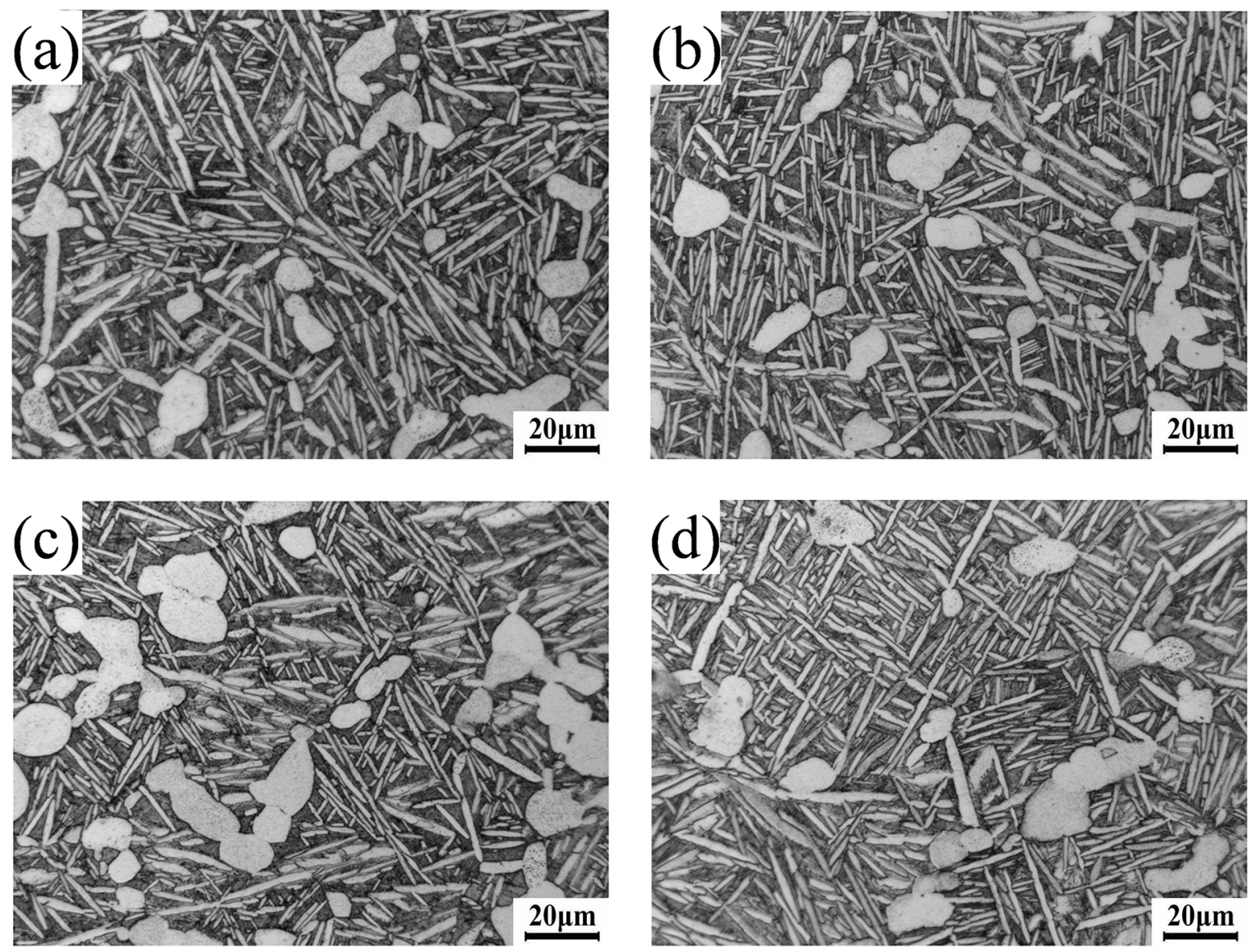

Figure 8. Micrographs of different loading zones after ILCF $\left(940^{\circ} \mathrm{C} / 60 \% / 0.1 \mathrm{~s}^{-1} / 2\right)$ under different cooling modes combined with given NTH $\left(975^{\circ} \mathrm{C} / 0.5 \mathrm{~h} / \mathrm{WQ}+930^{\circ} \mathrm{C} / 1.5 \mathrm{~h} / \mathrm{AC}\right)$ : (a), (b) WQ; (c), (d) AC ((a), (c) the first loading zone; (b), (d) the second oading zone). 


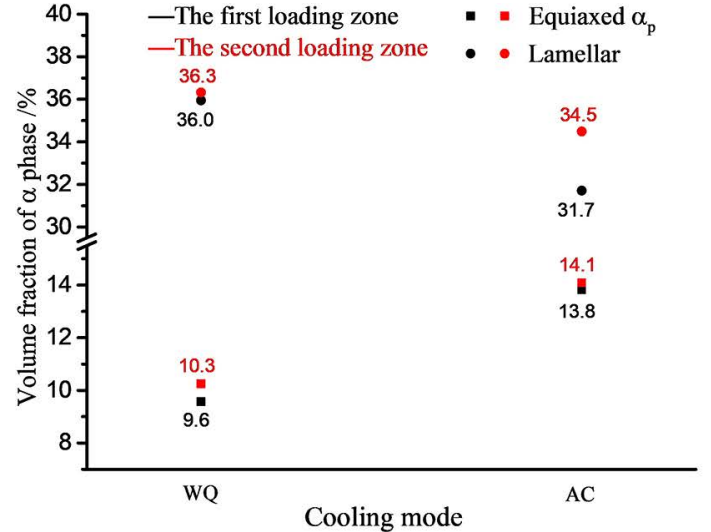

(a)

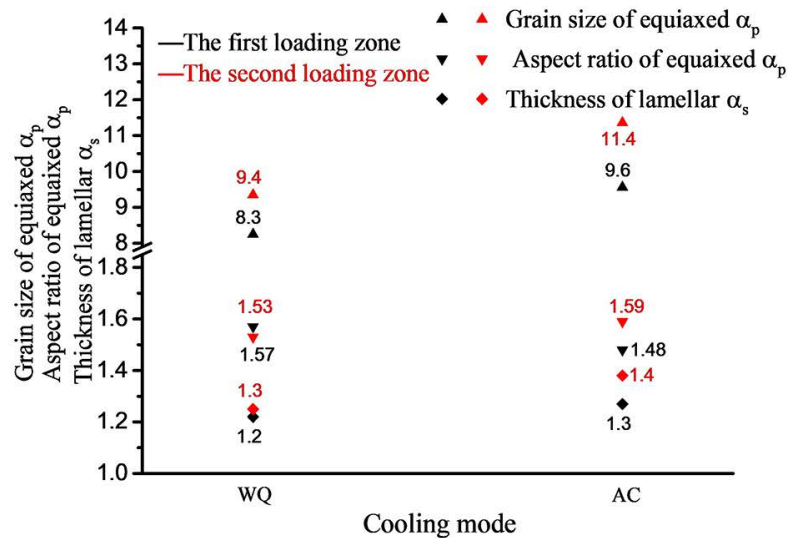

(b)

Figure 9. Microstructure parameters of different loading zones after ILCF $\left(940^{\circ} \mathrm{C} / 60 \% / 0.1 \mathrm{~s}^{-1} / 2\right)$ under different cooling modes combined with given $\mathrm{NTH}\left(975^{\circ} \mathrm{C} / 0.5 \mathrm{~h} / \mathrm{WQ}+930^{\circ} \mathrm{C} / 1.5 \mathrm{~h} / \mathrm{AC}\right)$ : (a) volume fraction of $\alpha$ phase; (b) average grain size and aspect of equiaxed $\alpha_{\mathrm{p}}$, thickness of lamellar $\alpha_{\mathrm{s}}$.
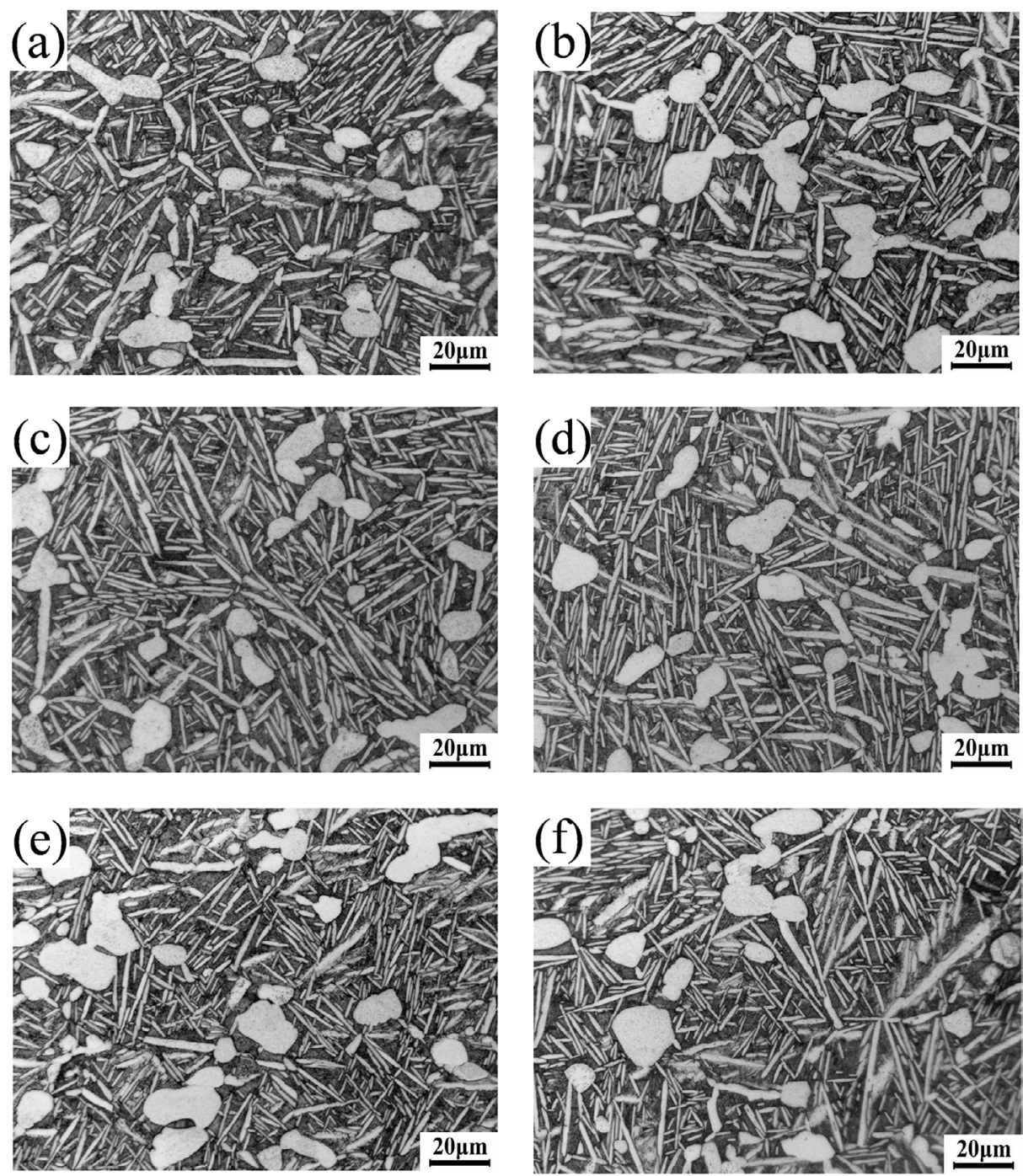

Figure 10. Micrographs of different loading zones after ILCF $\left(940^{\circ} \mathrm{C} / 60 \% / 0.1 \mathrm{~s}^{-1} / \mathrm{WQ}\right)$ under different loading passes combined with given $\mathrm{NTH}\left(975^{\circ} \mathrm{C} / 0.5 \mathrm{~h} / \mathrm{WQ}+930^{\circ} \mathrm{C} / 1.5 \mathrm{~h} / \mathrm{AC}\right)$ : (a), (b) one loading pass; (c), (d) two loading passes; (e), (f) three loading passes ((a), (c), (e) the first loading zone; (b), (d), (f) the second loading zone) 


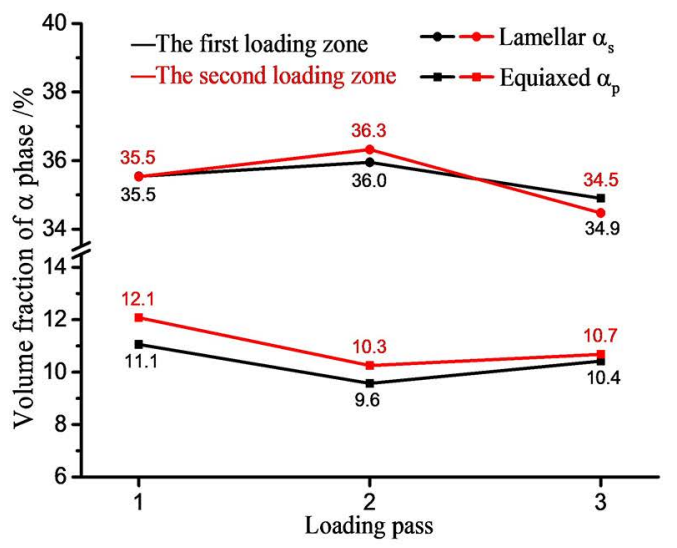

(a)

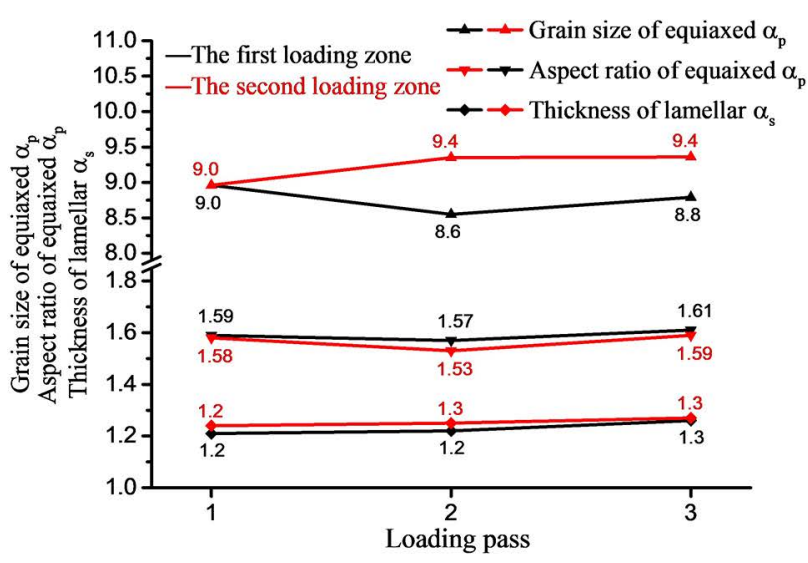

(b)

Figure 11. Microstructure parameters of different loading zones after ILCF $\left(940^{\circ} \mathrm{C} / 60 \% / 0.1 \mathrm{~s}^{-1} / \mathrm{WQ}\right)$ under different loading passes combined with given $\mathrm{NTH}\left(975^{\circ} \mathrm{C} / 0.5 \mathrm{~h} / \mathrm{WQ}+930^{\circ} \mathrm{C} / 1.5 \mathrm{~h} / \mathrm{AC}\right)$ : (a) volume fraction of $\alpha$ phase; (b) average grain size and aspect of equiaxed $\alpha_{\mathrm{p}}$, thickness of lamellar $\alpha_{\mathrm{s}}$.

large deformation (60\%) generates large amounts of crystal defects and distortion energy, and a considerable amount of them can be retained, which promotes the growth of equiaxed $\alpha_{p}$ during heat treatment. On the other hand, in three loading passes the equiaxed $\alpha_{\mathrm{p}}$ experienced multiple thermal cycles, which provides more time for $\alpha \rightarrow \beta$ phase transformation. The grain size of equiaxed $\alpha_{p}$ shows an increasing trend. This is because the deformation degree of each loading pass decreases with the increase of loading passes, thus the degree of flattening and elongation of equiaxed $\alpha_{p}$ decreases during ILCF. In addition, the equiaxed $\alpha_{\mathrm{p}}$ aggregates and merges after experiencing multiple thermal cycles.

The content of lamellar $\alpha_{\mathrm{s}}$ in both first and second loading zones decreases first and then increases, which shows a reverse variation trend to that of equiaxed $\alpha_{\mathrm{p}}$. The reason for the variation of lamellar $\alpha_{s}$ is the same as that in the section 3.1. Meanwhile, in three loading passes the uniformity of tri-modal microstructure in both loading zones is better compared with that in loading passes of one and two.

\section{Determination of Reasonable ILCF Conditions for tri-modal Microstructure}

From the analysis above, it is found that under different ILCF conditions combined with given NTH $\left(975^{\circ} \mathrm{C} / 0.5 \mathrm{~h} / \mathrm{WQ}\right.$ $+930^{\circ} \mathrm{C} / 1.5 \mathrm{~h} / \mathrm{AC}$ ), the obtained tri-modal microstructure of TA15 alloy shows some differences in constituent phases. Due to the harsh working conditions, TA15 Ti-alloy large-scale component not only needs to obtain a tri-modal microstructure, but also requires good uniformity in different loading zones and appropriate size, content and morphology of constituent phases. Zhou et al. ${ }^{6}$ found that equiaxed $\alpha_{\mathrm{p}}$ content above $20 \%$ provided very little for their increase of ductility, but had detrimental effects on high temperature properties. Sha et al. ${ }^{18}$ found that the creep properties improved with the increase of lamellar $\alpha_{\mathrm{s}}$ content, and the fracture toughness and impact properties strengthened as the thickness of lamellar $\alpha_{\mathrm{s}}$ increases. And more disordered lamellar $\alpha_{\mathrm{s}}$ will be good at hindering the movement of dislocations and cracks propagation due to the short effective sliding length ${ }^{19,20}$. Therefore, it is better to maintain $10-20 \%$ equiaxed $\alpha_{p}$, and more than $40 \%$ disordered and thicker lamellar $\alpha_{\mathrm{s}}$ in final tri-modal microstructure. Under given heat treatment $\left(975^{\circ} \mathrm{C} / 0.5 \mathrm{~h} / \mathrm{WQ}+930^{\circ} \mathrm{C} / 1.5 \mathrm{~h} / \mathrm{AC}\right)$, the appropriate ILCF conditions to obtain desirable tri-modal microstructure is $950^{\circ} \mathrm{C} / 0.1 \mathrm{~s}^{-1} / 3 / \mathrm{WQ}$.

\section{Conclusions}

1. For TA15 Ti-alloy after different isothermal local conventional forging (ILCF) conditions combined with near- $\beta+$ two-phase field heat treatments (NTH, $975 / 30 \mathrm{~min} / \mathrm{WQ}+930^{\circ} \mathrm{C} / 1.5 \mathrm{~h} / \mathrm{AC}$ ), the final microstructural constituents in both loading zones are similar, both of them are composed of equiaxed $\alpha_{\mathrm{p}}$, lamellar $\alpha_{\mathrm{s}}$ and transformed $\beta$ matrix.

2. As forging temperature increases from $930^{\circ} \mathrm{C}$ to $960^{\circ} \mathrm{C}$, the content of equiaxed $\alpha_{\mathrm{p}}$ decreases from $13.8 \%$ to $9.1 \%$ in first loading zone and from $13.4 \%$ to $8.9 \%$ in second loading zone while the content of lamellar $\alpha_{\mathrm{s}}$ increases from $30.7 \%$ to $38 \%$ in first loading zone and from $33.2 \%$ to $42.3 \%$ in second loading zone. As strain rate increases from $0.01 \mathrm{~s}^{-1}$ to $0.1 \mathrm{~s}^{-1}$, the content and size of equiaxed $\alpha_{\mathrm{p}}$ show a decreasing trend, reducing from $16.8 \%$ to $9.6 \%$ in the first loading zone and from $11.9 \%$ to $10.3 \%$ in the second loading zone, while the content of lamellar $\alpha_{\mathrm{s}}$ shows a slight upward trend. When forged at a higher strain rate of $0.1 \mathrm{~s}^{-1}$, the differences in the size, content and morphology of constituent phases are smaller in both loading zones. 
3. When cooled by WQ after forging, there are relatively less content and smaller grain size of equiaxed $\alpha_{p}$, while more and thinner lamellar $\alpha_{\mathrm{s}}$ are generated. The lamellar $\alpha_{\mathrm{s}}$ is relatively interlaced and disordered, and the differences in size, content and morphology of $\alpha$ phase in tri-modal microstructure are smaller in both loading zones. Under three loading passes forging, the uniformity of tri-modal microstructure is better in both loading zones.

4. According to the required tri-modal microstructure (10-20\% equiaxed $\alpha_{\mathrm{p}}$, and more than $40 \%$ disordered, and thicker lamellar $\alpha_{\mathrm{s}}$ ), considering the uniformity in the first and second loading zones, under given $\mathrm{NTH}\left(975^{\circ} \mathrm{C} / 0.5 \mathrm{~h} / \mathrm{WQ}+930^{\circ} \mathrm{C} / 1.5 \mathrm{~h} / \mathrm{AC}\right)$, the appropriate ILCF conditions is $950^{\circ} \mathrm{C} / 0.1 \mathrm{~s}^{-1} / 3 / \mathrm{WQ}$.

\section{Acknowledgement}

The authors would like to gratefully acknowledge the supports of the National Natural Science Foundation of China (51675432), Research Fund of the State Key Laboratory of Solidification Processing (NWPU) (156-QP-2016), Project of Science, Technology and Innovation Commission of Shenzhen Municipality (Grant No. JCYJ20170815163436211).

\section{References}

1. Leyens C, Peters M, eds. Titanium and Titanium Alloys: Fundamentals and Applications. 2nd ed. Weinheim: WileyVCH; 2003.

2. Froes FH, Caplan IL, eds. Titanium '92 Science And Technology. Warrendale: TMS; 1992.

3. Fan XG, Gao PF, Yang H. Microstructure evolution of the transitional region in isothermal local loading of TA15 titanium alloy. Materials Science and Engineering: A. 2011;528(6):2694-2703.

4. Yang H, Fan XG, Sun ZC, Guo LG, Zhan M. Recent developments in plastic forming technology of titanium alloys. Science China Technological Sciences. 2011;54(2):490-501.

5. Sun ZC, Liu L, Yang H. Microstructure evolution of different loading zones during TA15 alloy multi-cycle isothermal local forging. Materials Science and Engineering: A 2011;528(15):5112-5121.

6. Zhou YG, Zeng WD, Yu HQ. An investigation of a new nearbeta forging process for titanium alloys and its application in aviation components. Materials Science and Engineering: A. 2005;393(1-2):204-212.

7. Zhu JC, He D, Yang XW, Liu Y. EBSD study on dual heat treatment and microstructure evolution of TA15 titanium alloy. Rare Metal Materials and Engineering. 2013;42(2):382-386. [In Chinese]
8. Sun ZC, Han FX, Wu HL, Yang H. Tri-modal microstructure evolution of TA15 Ti-alloy under conventional forging combined with given subsequent heat treatment. Journal of Materials Processing Technology. 2016;229:72-81.

9. Sun ZC, Mao XJ, Wu HL, Yang H, Li JJ. Tri-modal microstructure and performance of TA15 Ti-alloy under near- $\$$ forging and given subsequent solution and aging treatment. Materials Science and Engineering: A. 2016;654:113-123.

10. Gao PF, Fan XG, Yang H. Role of processing parameters in the development of tri-modal microstructure during isothermal local loading forming of TA15 titanium alloy. Journal of Materials Processing Technology. 2017;239:160-171.

11. Sun ZC, Wang XQ, Zhang J, Yang H. Prediction and control of equiaxed a in near- $\beta$ forging of TA15 Ti-alloy based on BP neural network: For purpose of tri-modal microstructure. Materials Science and Engineering: A. 2014;591:18-25.

12. Fan XG, Yang H, Gao PF, Yan SL. Dependence of microstructure morphology on processing in subtransus isothermal local loading forming of TA15 titanium alloy. Materials Science and Engineering: A. 2012;546:46-52.

13. Gao PF, Yang H, Fan XG. Quantitative analysis of the microstructure of transitional region under multi-heat isothermal local loading forming of TA15 titanium alloy. Materials \& Design. 2011;32(4):2012-2020.

14. Gao XX, Zeng WD, Wang YB, Long Y, Zhang SF, Wang QJ. Evolution of equiaxed alpha phase during heat treatment in a near alpha titanium alloy. Journal of Alloys and Compounds. 2017;725:536-543.

15. Sun ZC, Guo SS, Yang H. Nucleation and growth mechanism of a-lamellae of Ti alloy TA15 cooling from an a $+\beta$ phase field. Acta Materialia. 2013;61(6):2057-2064.

16. Semiatin SL, Bieler TR. The effect of alpha platelet thickness on plastic flow during hot working of Ti-6Al-4V with a transformed microstructure. Acta Materialia. 2001;49(17):3565-3573.

17. Semiatin SL, Knisley SL, Fagin PN, Barker DR, Zhang F. Microstructure evolution during alpha-beta heat treatment of Ti-6Al-4V. Metallurgical and Materials Transactions A. 2003;34(10):2377-2386.

18. Sha AX, Li XW, Chu JP, Wen GH. Effect of heat treatment processes on impact property of TA15 alloy. Chinese Journal of Rare Metals. 2006;30:26-29.

19. Gao XX, Zeng WD, Li X, Zhou D, Xu JW, Wang QJ. Effect of boundary on the alpha phase precipitation in a near-alpha titanium alloy. Materials Letters. 2018;233:298-301.

20. Froes FH. Mechanical Properties and Testing of Titanium Alloys. In: Froes FH, ed. Titanium: Physical Metallurgy Processing and Applications. Materials Park: ASM International; 2015. p. 113-140. 